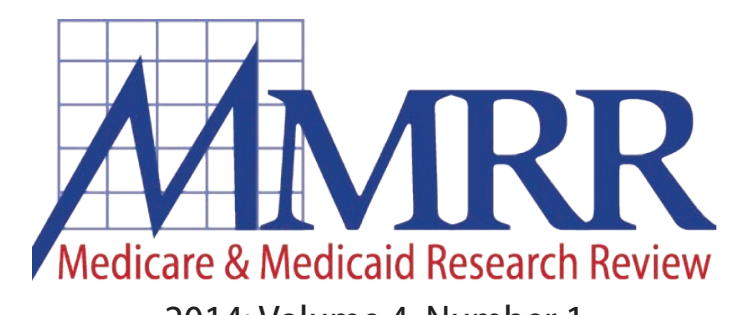

2014: Volume 4, Number 1

A publication of the Centers for Medicare \& Medicaid Services, Office of Information Products \& Data Analytics

\title{
The Medicaid Medically Improved Group: Losing Disability Status and Growing Earnings
}

\author{
Kathleen C. Thomas ${ }^{1}$ and Jean P. Hall ${ }^{2}$ \\ ${ }^{1}$ University of North Carolina at Chapel Hill-Cecil. G. Sheps Center for Health Services Research \\ ${ }^{2}$ University of Kansas-Institute for Health \& Disability Policy Studies
}

Objectives: Under the Ticket to Work and Work Incentives Improvement Act (PL 106-170), states may extend Medicaid Buy-In coverage to a medically improved group. Improved group coverage allows adults with disabilities to retain Medicaid coverage even once they lose disability status due to medical improvement, as long as they retain the original medical impairment. The goal of this paper is to describe who participated, the patterns of their participation, and employment outcomes.

Methods: The study population consists of all individuals $(\mathrm{n}=315)$ who participated in medically improved group coverage 2002-2009 in the seven states with coverage by 2009 (Arizona, Connecticut, Kansas, New York, North Carolina, Pennsylvania, and West Virginia). Linked data from state Medicaid Buy-In finder files and Social Security Administration Ticket Research and Master Earnings Files were used to describe improved group participants and their patterns of enrollment.
Results: Although enrollment has been limited, with 255 participants in 2009, it has doubled annually on average with little churning and dropout. Participants' earnings grew nearly 200 dollars per month after two years, likely reflecting increased work hours and/or higher pay rates.

Conclusions: Improved group participants represent an unusually successful group of individuals with disabilities, many of whom have recently moved off Social Security cash benefit rolls or who were diverted from them. Specifics of insurance eligibility and coverage for improved group participants are uncertain under the Affordable Care Act. The challenge remains to provide a pathway for adults with disabilities to increase work and assets without loss of adequate health insurance.

Keywords: disability, Medicaid, earnings, Affordable Care Act

ISSN: 2159-0354

doi: http://dx.doi.org/10.5600/mmrr.004.01.a02 


\section{Medicare \& Medicaid Research Review} 2014: Volume 4, Number 1

\section{Mission Statement}

Medicare \& Medicaid Research Review is a peerreviewed, online journal reporting data and research that informs current and future directions of the Medicare, Medicaid, and Children's Health Insurance programs. The journal seeks to examine and evaluate health care coverage, quality and access to care for beneficiaries, and payment for health services.

\section{http://www.cms.gov/MMRR/}

\section{U.S. Department of Health \& Human Services Kathleen Sebelius Secretary}

\section{Centers for Medicare \& Medicaid Services Marilyn Tavenner Administrator}

Editor-in-Chief

David M. Bott, Ph.D.

The complete list of Editorial Staff and Editorial Board members may be found on the MMRR Web site (click link): $\underline{\text { MMRR Editorial Staff Page }}$

Contact: $\underline{\text { mmrr-editors@cms.hhs.gov }}$

Published by the Centers for Medicare \& Medicaid Services.

All material in the Medicare \& Medicaid Research

Review is in the public domain and may be duplicated without permission. Citation to source is requested.

\section{Introduction}

Employment rates among people with disabilities are very low, 33.4 percent compared to 75.6 percent for people without disability in 2011 (the American Community Survey defines disability as having at least one of the following: serious difficulty with a hearing, visual, cognitive, or ambulatory disability, or difficulty with self-care or independent living; Erickson, Lee, \& von Schrader, 2013), despite antidiscrimination and accommodation requirements in the Americans with Disabilities Act (PL 101-336and PL 110-325). The employment rate among working age Social Security beneficiaries (who must meet a more stringent definition of disability: having a medically determined impairment lasting at least one year, or resulting in death, and unable to engage in substantial gainful activity) is even lower, 12.1 percent in 2007 (data from the Social Security Administration Ticket Research File; Mamun, O'Leary, Wittenburg, \& Gregory, 2011). Among those who are employed, less than 3 percent earn above the poverty level (Mamun et al., 2011). Households with adults with disabilities (defined from theSurveyofIncomeandProgramParticipation as at least one adult who used an assistive device for mobility; had difficulty with functional activity, activities of daily living or instrumental activities of daily living; had a developmental, mental, or emotional disability, or a condition that limited work) have significantly lower levels of income and assets than others, controlling for level of employment (U.S. Census Bureau, 2014; Parish, Grinstein-Weiss, Yeo, Rose, \& Rimmerman, 2010). Fear of loss of health insurance benefits has been cited as a major barrier to increased employment (White, Black, \& Ireys, 2005; MacDonald-Wilson, Rogers, Ellison, \& Lyass, 2003; Polack \& Warner, 
1996). This paper describes the experiences of a group of disabled individuals who successfully used an optional program to increase employment while maintaining Medicaid coverage.

Adults with disabilities have two pathways to Medicaid coverage. Those who are unable to engage in "substantial gainful activity," a level of earning slightly above the federal poverty level defined annually by the Social Security Administration, can qualify for Social Security disability benefits (SSA, 2013a). Individuals with limited income and resources qualify for Supplemental Security Income (SSI), which confers Medicaid eligibility in most states (Schneider, Elias, Garfield, Rousseau, \& Wachino, 2002). Individuals who have worked sufficient quarters qualify for Social Security Disability Insurance (SSDI) and may qualify for Medicaid in addition to Medicare once generally stricter income and asset criteria are met. When individuals work, Social Security benefits are reduced. SSI beneficiaries can retain Medicaid coverage by virtue of section $1619 \mathrm{~b}$ of the Social Security Act until their earnings reach about $\$ 3,000$ per month depending on their state (SSA, 2012). SSDI beneficiaries generally lose their cash assistance and disability status once earnings reach the substantial gainful activity level, about $\$ 1,040$ per month (SSA, 2013b), though some earnings can be disregarded for work incentive programs. Under the Patient Protection and Affordable Care Act (PL 111-148), these individuals may be eligible for narrower Medicaid benefits in states that implement the Medicaid expansion. The Social Security Administration encourages beneficiaries to work, but work jeopardizes their Medicaid coverage.

An optional Medicaid coverage category, called the Medicaid Buy-In for working adults, allows adults with disabilities to retain their Medicaid coverage even when their earnings rise above their state's Medicaid income eligibility threshold. Participants must meet Social Security disability criteria, but for their earnings, and pay a premium based on a sliding scale that varies by state. This basic Buy-In coverage increases allowable earnings for disabled Medicaid beneficiaries, but eligibility is still tied to disability. Medicaid Buy-Ins have been established in 45 states under the Ticket to Work and Work Incentives Improvement Act of 1999 (PL106-170), the Balanced Budget Act of 1997 (PL 105-33), and via a Medicaid 1115 waiver (MIG-RATS, 2012; Beauchamp, Ireys, \& Liu, 2007). States have flexibility to set income and asset limits, and these features affect participation and earnings. Participation in Buy-Ins across the states has been low, ranging from 1 to 1,035 per 10,000 working age people with disabilities (Ireys, Gimm, \& Liu, 2009). Some states have unearned income limits, which in effect limit the number of SSDI beneficiaries who meet eligibility criteria. State asset limits range from $\$ 2,000$ to none, and enrollment is higher in states with higher or no asset limits (Gimm, Davis, Andrews, Ireys, \& Liu, 2008). In 2011, mean annual earnings among participants were \$9,135 (Kehn, 2013). Among participants, earnings have largely remained below the substantial gainful activity limit, annualized to $\$ 12,000$ in 2011 for non-blind individuals, so that Social Security disability status is safeguarded (Ireys et al., 2009). State earned income limits range from $200 \%$ of the federal poverty level to none; earnings are higher in states where the limit is higher or nonexistent (Gimm et al., 2008). There is evidence that Buy-In participation is associated with increased earnings compared to what people would have earned otherwise (Shah, Mancuso, He, \& Kozak, 2012).

Under the Ticket to Work Act (PL 106-170), a state has the option to extend Medicaid BuyIn expanded coverage to a medically improved group, for people who first enrolled in the basic Buy-In. Improved group coverage allows adults with disabilities to retain Medicaid coverage even 
once they lose Social Security disability status due to medical improvement, as long as they retain the original medical impairment. The improved group option loosens the connection between Medicaid eligibility and disability, while acknowledging that continued access to Medicaid coverage is essential to prevent decline back to disability status. Examples of possible medical improvement participants would include a person with mental illness who still requires regular psychotherapy and medications to remain stable, or a person with renal failure who no longer requires dialysis due to a kidney transplant, but must follow a strict regimen of anti-rejection medications to maintain the success of the transplant. Nine states have included the improved group as part of their Buy-In to date, with a total national enrollment of 315 people. The experiences of improved group participants are unexplored. The goal of this paper is to provide cross-state analyses of improved group participants in order to describe who participated, the patterns of their participation, and employment outcomes.

\section{Methods}

\section{Study Population}

The study population consists of all individuals ( $\mathrm{n}=315$ ) who participated in medically improved group coverage any time from beginning enrollment in 2002 through 2009 in the seven states that had implemented improved group coverage by 2009 (Arizona, Connecticut, Kansas, New York, North Carolina, Pennsylvania, and West Virginia).

\section{Data Sources}

Data were compiled from state Medicaid Buy-In finder files, which contain dates of participation in the improved and basic Buy-In groups, demographics, and a personal identification number for linking with other files. These data were linked with administrative data from the Social Security Administration Ticket Research and Master Earnings Files (Hildebrand, et al., 2010; MPR, 2006; Panis et al., 2000). The Ticket Research File contains current and historical data on SSI and SSDI beneficiaries aged 18 to 64 between 1996 and 2009; it was used to identify an individual's primary disabling condition. The Master Earnings File contains earnings reported on an annual basis by nearly all workers to the Internal Revenue Service on tax forms beginning in 1951. Data were compiled and analyzed by Mathematica Policy Research under contract with the Centers for Medicare \& Medicaid Services (CMS). Mathematica complied with all confidentiality provisions specified in data sharing agreements. The authors had access to aggregate data only, specified in advance of analyses through a proposal made to Mathematica. Each state with an improved group provided a letter of support as a required part of the proposal.

\section{Measures}

Demographic measures capture age at enrollment in the medically improved group (in years), gender (female), and race (minority). Primary disabling condition is the primary condition on which an individual's Social Security disability determination is based (Panis et al., 2000). It is comprised of five categories: mental illness, mental retardation, musculoskeletal system, sensory impairment, and all other conditions (infectious diseases; neoplasms; endocrine diseases; blood diseases; diseases of the nervous, circulatory, respiratory, digestive, or genitourinary systems; diseases of the skin; congenital anomalies; injuries; or other; Hildebrand et al., 2010).

Patterns of enrollment were described by duration of enrollment, gaps in enrollment, and 
rate of drop out. Duration of enrollment in a Medicaid Buy-In basic or improved group was measured as the sum of years with at least one month of enrollment. Gaps in enrollment in the improved group were measured in months. Mean gap time is the average time in months among all individuals with a gap, since no individual had more than one gap. Individuals are identified as having dropped out if they disenrolled from the improved group and did not re-enroll. For year 1 of enrollment, drop outs are those who were enrolled for less than one year and then dropped out (measured for all who enrolled in the improved group in January 2009 or earlier); for year 2 of enrollment, drop outs are those who were enrolled for 12 consecutive months, but dropped out before 24 months (restricted to those who enrolled in the improved group in January 2008 or earlier), and for year 3 of enrollment, drop outs are those who enrolled for 24 consecutive months, but dropped out before 36 months (restricted to those who enrolled in the improved group in January 2007 or earlier). New York's improved group participants were excluded from the analysis of participants who had gaps or dropped out due to a data reporting error.

Earnings were measured by income reported to the Internal Revenue Service from the Master

Exhibit 1. Improved Group Participant Characteristics

\begin{tabular}{lcc}
\hline Characteristics & Percent & Mean(SD) \\
\hline Age at enrollment & - & $42(3.6)$ \\
Female & $54.29 \%$ & - \\
Minority & $10.48 \%$ & - \\
Disability type $^{1}$ & & - \\
$\quad$ Mental Illness & $44.59 \%$ & - \\
$\quad$ Mental Retardation & $14.86 \%$ & - \\
$\quad$ Musculoskeletal System & $9.46 \%$ & - \\
$\quad$ Sensory Impairment & $5.41 \%$ & - \\
$\quad$ All Other & $25.68 \%$ & - \\
\hline
\end{tabular}

NOTE: 'among $n=74$ in the Ticket Research File

SOURCE: 2009 Medicaid Buy-In finder files; 2009 Ticket Research File
Earnings File (Panis et al., 2000). All earnings are adjusted to reflect 2009 dollars.

\section{Analytic Methods}

Descriptive statistics characterize improved group participants and their patterns of enrollment over time. Two-tailed $\mathrm{T}$ tests are used to test the hypothesis that there was a change in earnings over time in the cohort of individuals who were enrolled in the improved group for two consecutive years $(n=187)$.

\section{Results}

Improved group participant characteristics are shown in Exhibit 1. There have been 315 participants nationally through 2009. Mean age varied little across the states $(S D=3.6)$. Forty five percent of participants for whom primary diagnosis was known $(\mathrm{n}=74)$ had a severe mental illness or other mental disorder.

Medically improved group annual enrollment is shown in Exhibit 2. Enrollment began in 2002; 255 people were enrolled in 2009. Enrollment growth has averaged 200 percent a year over this period of time. Growth averaged nearly 300 percent in the first 3 years, slowing to just under 50 percent in the latter 4 years.

Exhibit 2. Improved Group Enrollment by Year

Percent of all

\begin{tabular}{lcc} 
Year & Number & buy-in enrollees \\
\hline 2002 & 3 & $0.06 \%$ \\
2003 & 11 & $0.12 \%$ \\
2004 & 23 & $0.16 \%$ \\
2005 & 59 & $0.28 \%$ \\
2006 & 97 & $0.38 \%$ \\
2007 & 128 & $0.44 \%$ \\
2008 & 173 & $0.45 \%$ \\
2009 & 255 & $0.50 \%$ \\
\hline
\end{tabular}

SOURCE: 2009 Medicaid Buy-In finder files 
Patterns of enrollment in the improved group are shown in Exhibit 3. Participants stayed in basic Buy-In coverage for one year on average before moving into the medically improved group. Although enrollment in the improved group has been small, enrollees remain in the program for over two years on average. Sixteen percent of enrollees drop out during their first year, but only 3 percent have gaps in enrollment over time (based on data from six states, $\mathrm{n}=203$ ).

Medically improved group participants achieved mean earnings of $\$ 16,458$ in 2009,40 percent above the annualized Social Security Administration substantial gainful activity limit (for non-blind individuals) for that year and
52 percent above the federal poverty level for an individual. Between 2006 and 2009, mean earnings among all improved group participants ranged from $\$ 15,590$ in 2006 to $\$ 17,237$ in 2008 . Among the cohort of improved group participants with two consecutive years of participation, mean earnings in their second year of participation were significantly different from earnings in the year prior to enrollment ( $\mathrm{p}<0.05$; Exhibit 4). Improved group participant earnings grew $15 \%$, equal to nearly 200 dollars per month, by their second year of participation. The cohort of individuals with two consecutive years of participation upon which this analysis is based represents about 60 percent of all improved group participants.

Exhibit 3. Improved Group Patterns of Enrollment

\begin{tabular}{lcccc}
\hline Variable & Percent & Mean & Min & Max \\
\hline Prior basic coverage years & - & 0.9 & 0.0 & 6.1 \\
Years in improved group & - & 2.4 & 1.0 & 7.0 \\
Any enrollment gap ${ }^{1}$ & $3 \%$ & - & - & - \\
$\quad$ Gap months & - & 7.2 & 2 & - \\
Drop out & & & - & - \\
$\quad$ Year 1 & $16 \%$ & - & - & - \\
$\quad$ Year 2 & $19 \%$ & - & -
\end{tabular}

NOTE: ${ }^{1}$ Analyses based on data from 6 states due to a reporting error $(n=203)$

SOURCE: 2001-2009 Medicaid Buy-In finder files

Exhibit 4. Improved Group Earnings Over Time

\begin{tabular}{lcc}
\hline Variable & Mean & $\begin{array}{c}\text { \% change from year } \\
\text { prior to enrollment }\end{array}$ \\
\hline Earnings level in $2009^{1}$ & $\$ 16,458$ & - \\
Mean earnings ${ }^{2}$ & & - \\
$\quad$ In year before enrollment & $\$ 15,046$ & $9.14 \%$ \\
$\quad$ In year of enrollment & $\$ 16,422$ & $15.24 \%{ }^{*}$ \\
$\quad$ In year after enrollment & $\$ 17,339$ & \\
\hline NOTES: ${ }^{1}$ among enrollees with positive earnings in 2009 $\mathrm{n}=233$ & \\
${ }^{2}$ Cohort of those enrolled in the improved group for 2 consecutive years, $\mathrm{n}=187$ & \\
${ }^{*} \mathrm{p}<0.05$ & \\
SOURCE: 2009 Medicaid Buy-In Finder Files; 2009 SSA Master Earnings File &
\end{tabular}




\section{Discussion}

The findings presented here indicate that the medically improved group, an optional coverage group in Medicaid Buy-Ins for working adults with disabilities, may be especially important for people with mental illness. Improved group coverage is limited to people who originally received basic coverage in a Buy-In program, have experienced medical improvement to the point where they lose disability status, but retain the original medical impairment. These are strict criteria and enrollment across the seven states that offer coverage has been low, with 255 participants in 2009. Nevertheless, enrollment has doubled annually on average with little churning and drop-out. Medically improved group participants achieved mean earnings of $\$ 16,458$ in 2009 . This level of earnings is nearly twice as high as mean earnings among basic buy-in participants in 2009, 52 percent higher than the federal poverty level for an individual, and 40 percent higher than the annualized Social Security Administration substantial gainful activity limit (for non-blind individuals) for that year (Kehn, Croake, \& Schimmel, 2010). Most importantly, data indicate that participants' earnings grow in their first two years of participation, likely reflecting increased work hours and/or higher pay rates.

\section{Limitations}

The administrative data used for these analyses provide a unique opportunity to look across the states at the entire population of participants in a small, but quickly growing, program. Nevertheless, variations in state program eligibility criteria and reporting give rise to several limitations. First, nearly half of participants never received Social Security benefits, so they do not appear in the Ticket Research File and their disabling condition is not available for analysis. The size of this group may, in part, reflect the fact that West Virginia has a low unearned income limit, equal to or less than the SSI benefit plus $\$ 20$, which would limit participation by SSDI beneficiaries. To the extent that participants who never received Social Security benefits represent a different mix of disabling conditions from Social Security beneficiaries, the distribution of conditions reported here may be skewed. Second, earnings were measured by income reported to the Internal Revenue Service from the Master Earnings File. If an individual's earnings were low enough in a given year that they did not have to be reported, they would not be included in the analyses. Cash earned from casual employment and earnings from sheltered workshops may also be excluded. To the extent that first dollar earnings are not captured, the reported level and growth in earnings may be conservative. Third, the analysis of gaps in participation and drop-out was based on six of the seven states due to a reporting error. To the extent that the omitted state was different from the others, reported patterns of enrollment may be biased. Additional data on the context and rationale for people's participation and patient-centered outcomes would be ideal. The small population prevents state-level analyses, but comparisons between states would provide insights into factors that facilitate participation. Qualitative data on experiences of participants will be important to consider in future research as well.

\section{Implications}

Improved group participants represent an unusually successful group of individuals with disabilities, many of whom have recently moved off Social Security cash assistance rolls or who were diverted from those rolls through availability of Medicaid coverage via a Buy-In program. It may be that knowing about the improved group option provides 
basic buy-in enrollees an incentive to find ways to increase work so that disability status is lost. Or, it may be that improved group participants would have increased their work even in the absence of the improved group option, but this option provides a valued level of health coverage that supports their work efforts. The significant level of earnings and growth in earnings over time, among improved group participants, warrant further study to explore if this program facilitates earnings growth or simply provides an important pathway out of dependence for those ready to work more.

The success of this group raises questions about its small size and growth. Improved group programs opened gradually across the seven states; all seven programs were not in operation until 2009. To some extent then, growth represents program expansion to a new state rather than increased uptake within states. States consistently report that program outreach and implementation protocol are important factors affecting enrollment in the Medicaid buy-in programs as well (Kehn, 2013). It may be that buy-in participants were unaware of the improved group option, that states were cautious in their implementation of this group-due to challenges in determining medical improvement with a constant underlying condition without relying on work-related criteria-and/ or that many basic group enrollees were reluctant to increase their earnings to a point where they would lose Social Security disability status. Crossstate mixed methods analysis of improved group implementation processes could provide valuable insights regarding facilitators and barriers of shifting into the improved group.

Another issue of concern is that specifics of insurance eligibility and coverage, for improved group participants and other individuals who have increased their earnings enough to lose disability status, are uncertain under the Affordable Care Act (PL 111-148). As guidance stands, improved group participants will be evaluated for insurance eligibility based on their current eligibility for a Medicaid program where long-term services and supports are covered (Federal Register, 2012). If an improved group state were to drop this eligibility group, these participants, and others like them who never enrolled in an improved group program, would be evaluated for insurance eligibility based on their income (Federal Register, 2012). Given participants' earnings, some would qualify for new Medicaid in states that implement the Medicaid expansion. To date, the seven states that have implemented improved group coverage represent the full range of stances on Medicaid expansion: Arizona, Connecticut, and New York have decided to proceed with the Medicaid expansion; West Virginia has expressed interest in an expansion, but does not have a plan in place; Pennsylvania is considering an alternative model for expansion that would, nevertheless, make use of federal subsidies; Kansas is leaning away from expansion; and North Carolina has decided against it (ABC, 2013). Others would qualify for subsidized health insurance through the health insurance exchanges. In states without a Medicaid expansion, some would fall through the cracks, qualifying neither for a regular Medicaid program nor for subsidized health insurance through the exchanges.

Although the Affordable Care Act stipulates important elements of insurance for insured people with medical impairments, such as elimination of preexisting condition exclusions and explicit inclusion of mental health and habilitative care as essential benefits, there remain areas of uncertainty in coverage that will be available from the new Medicaid and private health insurance policies on the exchanges. First, after a state benchmark plan is chosen, although states can no longer reduce the actuarial value of a plan below the benchmark, there is still uncertainty about the depth and breadth of specific 
covered services (CCIIO, 2012; Weiner, 2012). Second, since the definitions of mental health, substance abuse, and behavioral healthcare treatment are open to interpretation, there remains uncertainty about whether or not plans will cover specific services or conditions (Sarata, 2011). Third, because habilitative services are rarely included in current plans, the guidance leaves room for significant variation and uncertainty over the scope of these services (CCIIO, 2012; CCIIO, 2011). It is likely that new plans available through the exchanges will not provide the longterm supports available through regular Medicaid plans. Future research should assess the adequacy of available health insurance to meet the needs of individuals with disabilities who work.

The findings presented here highlight the success of a small group of individuals supported by generous Medicaid coverage. New guidance from the Centers for Medicare \& Medicaid Services for implementation of the ACA details steps to preserve this group's access to services (Federal Register, 2012). Now, the challenge remains to provide a pathway for all adults with disabilities to increase work and assets and move beyond disability without loss of adequate health insurance.

\section{Disclaimer}

The authors have been requested to report any funding sources and other affiliations that may represent a conflict of interest. The authors reported that there are no conflict of interest sources. The views expressed in this article are those of the authors and do not represent official policy of the Department of Health and Human Services.

\section{Correspondence}

Kathleen C. Thomas, M.P.H., Ph.D., University of North Carolina at Chapel Hill, Cecil. G. Sheps Center for Health Services Research, 725 Martin Luther King Jr. Blvd., CB 7590, Chapel Hill, NC, 27514, kathleen_ thomas@unc.edu, Tel. 919-966-3387

\section{Acknowledgments}

We would like to acknowledge the contributions of Kristin Andrews of Mathematica Policy Research.

\section{Financial Disclosure}

This research was made possible by funding from the Centers for Medicare and Medicaid Services under contract and via Medicaid Infrastructure Grant Awards to the states of North Carolina and Kansas.

\section{References}

ABC The Advisory Board Company. (2013). Where each state stands on ACA's Medicaid expansion: A roundup of what each state's leadership has said about their Medicaid plans. Retrieved from http://www.advisory.com/Daily-Briefing/ Resources/Primers/MedicaidMap\#lightbox/0/

Beauchamp, J., Ireys, H., \& Liu, S. (2007). A government performance and results act (GPRA) report: The status of the medicaid infrastructure grants program as of December 31, 2006. Mathematica Policy Research, Inc. Retrieved from http://www.mathematica-mpr.com/publications/ pdfs/disability/GPRA_09.pdf

CCIIO Center for Consumer Information and Insurance Oversight. (2011). Essential health benefits bulletin. Retrieved from http://cciio. cms.gov/resources/files/Files2/12162011/ essential_health_benefits_bulletin.pdf

CCIIO Center for Consumer Information and Insurance Oversight, and Centers for Medicare and Medicaid Services. (2012). Frequently asked questions on essential health benefits bulletin. Retrieved from http://cciio.cms.gov/resources/ files/Files2/02172012/ehb-faq-508.pdf

Erickson, W., Lee, C., \& von Schrader, S. (2013). Disability Statistics from the 2011 American Community Survey (ACS). Ithaca, NY: Cornell 
University Employment and Disability Institute (EDI). Retrieved Oct 22, 2013 from www. disabilitystatistics.org

Federal Register. The Daily Journal of the United States Government. (2012). Medicaid program; eligibility changed under the affordable care act of 2010, 77(57). Retrieved from https://www.federalregister.gov/articles/ 2012/03/23/2012-6560/medicaid-programeligiblity-changes-under-the-affordable-careact-of-2010

Gimm, G., Davis, S. R., Andrews, K. L., Ireys, H. T., \& Liu, S. (2008). The three E's: enrollment, employment, and earnings in the Medicaid buyin program, 2006. Final report April 11, 2008. Mathematica Policy Research, Inc.

Hildebrand, L., Kosar, L., Page, J., Smither, C., Loewenberg, M., Phelps, D., \& Justh, N. (2010). User's guide for the ticket research file: TRF07, data from January 1994 to December 2007. Mathematica Policy Research, Inc.

Ireys, H. T., Gimm, G., \& Liu, S. (2009). The effects of state policy decisions on the employment and earnings of Medicaid buyin participants in 2006. Journal of Disability Policy Studies, 20(3), 142-154. http://dx.doi. org/10.1177/1044207309333695

Kehn, M. (2013). Enrollment, employment, and earnings in the Medicaid buy-in program, 2011. Final Report May 20, 2013. Mathematica Policy Research, Inc.

Kehn, M., Croake, S., \& Schimmel, J. (2010). A government performance and results (GPRA) report: the status of Medicaid infrastructure grants program as of 12/31/09. Final Report December 30, 2010. Mathematica Policy Research, Inc.
MacDonald-Wilson, K. L., Rogers, S. E., Ellison, M. L., \& Lyass, A. (2003). A study of the social security work incentives and their relation to perceived barriers to work among persons with psychiatric disability. Rehabilitation Psychology, 48(4), 301-309. http://dx.doi.org/10.1037/00905550.48 .4 .301

Mamun, A., O'Leary, P., Wittenburg, D. C., \& Gregory, J. (2011). Employment among social security disability program beneficiaries, 1996-1997. Social Security Bulletin, 71(3), 12-34.

MIG-RATS Medicaid Infrastructure Grant Research Assistance to States. (2012). Medicaid buy-in state summary 2012. Retrieved from http://www.migrats.org/

MPR: Mathematica Policy Research (2006). Draft list of variable in selected data sources on disability, program participation, health, and employment. Mathematica Policy Research, Inc.

Panis, C., Euller, R., Grant, C., Bradley, M., Peterson, C., Hirscher, R., \& Steinberg, P. (2000). SSA Program Data User's Manual. Rand Corporation.

Parish, S. L., Grinstein-Weiss, M., Yeo, Y. H., Rose, R. A., \& Rimmerman, A. (2010). Assets and income: disability-based disparities in the United States. Social Work Research, 34(2), 71-82. http://dx.doi.org/10.1093/swr/34.2.71

Polak, P. \& Warner, R. (1996). The economic life of seriously mentally ill people in the community. Psychiatric Services (Washington, D.C.), 47, 270-274. PubMed

Sarata, A. K. (2011). Mental health parity and the patient protection and affordable care act of 2010. Congressional Research Service.

Schneider, A., Elias, R., Garfield, R., Rousseau, D., \& Wachino, V. (2002). The Medicaid resource 
book. The Kaiser Commission On Medicaid and The Uninsured.

Shah, M. F., Mancuso, D. C., He, L., Kozak, S. (2012). Evaluation of the Medicaid buyin program in Washington state: Outcomes for workers with disabilities who purchase Medicaid coverage. Journal of Disability Policy Studies, 22(4), 220-229. http://dx.doi. org/10.1177/1044207311427162

SSA: Social Security Administration (2013a). 2013 Red book: A summary guide to employment supports for persons with disabilities under the social security disability insurance and supplemental security income programs. Office of Disability and Income Security Program, SSA Publication No. 64-030.

SSA Social Security Administration (2012). SSA SI 02302.00 charted threshold amounts. Retrieved from https://secure.ssa.gov/apps10/poms.nsf/ $\operatorname{lnx} / 0502302200$

SSA: Social Security Administration (2013b). Substantial gainful activity. Retrieved from https://secure.ssa.gov/apps10/poms.nsf/ $\ln x / 0502302200$

U.S. Census Bureau (2014). Survey of Income and Program Participation. Retrieved from http:// www.census.gov/sipp/

Weiner, J. (2012). The ACA's 50-state 'essential health benefits' tangle: Autism advocates wary of losing hard-won coverage. LDI Health Economist.

White, J. S., Black, W. E., \& Ireys, H. T. (2005). Explaining enrollment trends and participant characteristics of the Medicaid Buy-In program, 2002-2003. Mathematical Policy Research, Inc. 